\title{
Technology is becoming a Hypercortext
}

\section{Yair Neuman ${ }^{1}$}

A review of The Semantic Sphere 1: Computation, Cognition and Information Economy, by Pierre Lévy. ISTE Ltd. and John Wiley and Sons Inc., 2011; 381 pages.

Pierre Lévy is a leading visionary thinker who holds Canada Research Chair in Collective Intelligence. In his new book The Semantic Sphere Lévy is making another step toward a better understanding of the relations between information technology and the human mind from a semiotic interdisciplinary perspective. Let us start the review by acknowledging the fact that post-modernism as the historical intellectual venture of critically reflecting on modernism has put into question any attempt to provide a grand picture of reality - whether the real, the imagined, or the symbolic. In this context, Lévy's book is thought-provoking because it attempts to provide a grand picture by taking some of post-modernism's basic tenets as its building blocks. Lévy acknowledges the fragmentation of knowledge and its distribution in a rhizome kind of structure. Rather than being organized around centres, knowledge has become distributed in "scale free" networks where centres such as the mean have lost their sense. This revolution in the history of knowledge has reached a critical tipping point. On the one hand, information has become comprehensive, available, democratic, and free to an extent unfamiliar in human history. On the other hand, the loss of a centre has left us perplexed.

Information technology (IT) has a major role in the fragmentation of knowledge but Lévy considers IT not only as a "thantalic" force that breaks traditional structures of knowledge, but also as a constructive force through which "collective intelligence" may emerge. The promise of IT for enabling collective intelligence is far from trivial. The huge quantity of digital knowledge cannot be trivially scaled up into "collective intelligence". Currently, we are at the phase of "collected" intelligence and the challenge is to turn this huge collection into a meaningful force, i.e., collective intelligence.

Lévy, who was one of the first thinkers to discuss collective intelligence, suggests that in order to scale up collected into collective intelligence, we should develop a kind of a meta-language or meta-representation that he describes as IEML:

1 Author's address: Yair Neuman, Department of Education, Ben-Gurion University of the Negev, Israel; email: yneuman@bgu.ac.il. 
Information Economy Meta Language. The details of this meta-language are not discussed in this book but only the justification for developing it.

This meta-language should result in a "semantic sphere" where "center is everywhere and where circumference is nowhere" (Lévy 2011: 31). The IEML semantic sphere is actually a construct that aims to serve as a "Hypercortext". The meaning of this sphere as a Hypercortext is clarified in semiotic terms, but the idea is of augmented intelligence where the limit line of the human mind is extended through another layer of symbolic systems that aims to add value to the previous symbolic layers of our mind.

It is clear that information is a key term in this context. Levy suggests that not only do signs used by human beings categorize the world along sensory-motor dimensions, but they also categorize the operations we perform on the categories (Lévy 2011: 62). This is a classical Piagetian idea applied through semiotic terminology. The idea is that human beings use signs in a reflective manner. We do not only operate on and in the world, we do not only categorize the world, but we may mentally turn our mental operations into an object of reflection.

The conclusion is that symbolism opens to cognition "a practically unlimited dimension of recursively constructive complexity" (Lévy 2011: 63). This is a highly important point made by Lévy. The extension of cognition beyond the limit line of our brains is possible through the modern technology that enables not only collective intelligence but the projection of reflective activities into the platform of collective intelligence. The semantic universe is this realm of abstract categories human cognition processes through symbolic systems going far beyond the traditional symbolic system we have hitherto known.

Advances in the human sciences, so argues Lévy, are to be made by "a computable formalization of symbolic structures and relationships among semantic qualities" (Lévy 2011: 120). In this context, the IEML is a system of "semantic coordinates" (Lévy 2011: 122) that aims to allow us to represent value/meaning and their flow. That is, IEML should provide an instrument "for observing human symbolic life" (Lévy 2011: 131).

Lévy is a visionary thinker who provides stimulating ideas from a wide intellectual perspective. However, the IEML itself is the subject of the second proposed volume and therefore it remains to be seen whether, beyond the visionary ideas presented in this book, the meta-language he proposes will fulfill the great expectations put on its shoulders.

\section{References}

Lévy, Pierre 2011. The Semantic Sphere 1: Computation, Cognition and Information Economy. Hoboken, etc.: ISTE Ltd. and John Wiley and Sons Inc. 